\title{
The relationship between pain and eating among overweight and obese individuals with osteoarthritis: An ecological momentary study
}

\author{
Karmel W Choi MA , Tamara J Somers PhD², Michael A Babyak PhD², Kathleen J Sikkema PhD , \\ James A Blumenthal $\mathrm{PhD}^{2}$, Francis J Keefe $\mathrm{PhD}^{2}$
}

KW Choi, TJ Somers, MA Babyak, KJ Sikkema, JA Blumenthal, FJ Keefe. The relationship between pain and eating among overweight and obese individuals with osteoarthritis: An ecological momentary study. Pain Res Manag 2014;19(6):e159-e163.

BACKGROUND: Osteoarthritis (OA) patients who are overweight or obese report higher levels of pain compared with their normal-weight OA counterparts. Evidence suggests that overweight or obese OA patients also experience pain relief from eating foods high in calories, fat or sugar. Eating to alleviate pain may be problematic because it can lead to additional weight gain, which may contribute to heightened pain.

OBJECTIVES: To investigate the relationship between pain and food intake using ecological momentary assessments in a sample of 71 overweight and obese OA patients.

METHODS: Participants completed two consecutive days of diary entries in which they recorded their levels of pain, mood and food intake throughout the day. Data were analyzed using generalized estimating equations that modelled pain as a predictor of calorie, fat and sugar intake. All models were adjusted for sex, body mass index, negative mood, time and treatment history.

RESULTS: Pain significantly predicted calorie $(\mathrm{Z}=2.57 ; \mathrm{P}=0.01)$ and fat intake ( $\mathrm{Z}=1.99 ; \mathrm{P}=0.05)$.

CONCLUSIONS: Using ecological momentary assessments as a novel approach, the present study provides preliminary data supporting a relationship between pain and food intake among overweight and obese OA patients. Continued advances in our understanding of the relationship between pain and eating behaviour may help to optimize intervention strategies for these patients.

Key Words: BMI; Eating; Ecological momentary assessments (EMA); Obesity; Osteoarthritis; Pain; Weight

\section{Le lien entre la douleur et l'alimentation chez les personnes qui font de l'arthrose et qui font de l'embonpoint ou sont obèses : une étude écologique momentanée}

HISTORIQUE : Les patients qui font de l'arthrose et qui font de l'embonpoint ou sont obèses déclarent un niveau de douleur plus important que leurs homologues qui font de l'arthrose et dont le poids est normal. D'après les données probantes, les patients qui font de l'arthrose et qui font de l'embonpoint ou sont obèses voient leur douleur soulagée par la consommation d'aliments riches en calories, en matières grasses ou en sucre. Il peut être problématique de manger pour soulager la douleur, car cette habitude peut favoriser la prise de poids, ce qui peut contribuer à accroître la douleur. OBJECTIFS : Explorer le lien entre la douleur et la consommation d'aliments au moyen d'évaluations écologiques momentanées auprès d'un échantillon de 71 patients qui font de l'arthrose et qui sont obèses ou font de l'embonpoint.

MÉTHODOLOGIE : Pendant deux jours consécutifs, les participants ont inscrit dans un journal leur niveau de douleur, leur humeur et leur consommation d'aliments tout au long de la journée. Les chercheurs ont analysé les données au moyen d'équations d'estimation généralisées faisant appel à un modèle de douleur comme prédicteur de consommation de calories, de matières grasses et de sucre. Tous les modèles ont été rajustés compte tenu du sexe, de l'indice de masse corporelle, de l'humeur négative, du moment et des antécédents thérapeutiques.

RÉSULTATS : La douleur était un prédicteur important de consommation de calories $(Z=2,57, P=0,01)$ et de matières grasses $(Z=1,99, P=0,05)$. CONCLUSIONS : Au moyen d'une démarche novatrice d'évaluations écologiques momentanées, la présente étude fournit des données préliminaires qui appuient un lien entre la douleur et la consommation d'aliments chez les patients qui font de l'arthrose et qui sont obèses ou font de l'embonpoint. Notre compréhension croissante du lien entre la douleur et les comportements liés à l'alimentation pourrait contribuer à optimiser les stratégies interventionnelles auprès de ces patients.

to modulate various internal experiences including negative mood (26-28) and psychological stress (29,30). Notably, experimental studies from animal and human models have shown that these foods can also lead to pain relief (17-25), possibly by modulating the endogenous opioid system $(31,32)$ and reducing activation of brain regions associated with pain (19). There is additional evidence suggesting that overweight and obese individuals may be especially susceptible to eating to attain such physiological effects $(33,34)$. Given that consuming foods high in calories, fat and sugar can be experienced as a potent source of pain relief, it is possible that some overweight or obese OA patients turn to greater intake of such foods when they experience pain. In turn, this type of eating could lead to additional weight gain, ultimately resulting in greater pain and disability for these overweight or obese OA patients. However, to our knowledge, this clinically relevant behaviour has not yet been investigated in this population. Ences high in calories, fat and sugar, can provide pain relief (17-25). The consumption of foods high in calories, fat or sugar has been shown

${ }^{1}$ Psychology and Neuroscience, Duke University; ${ }^{2}$ Duke University Medical Center, Durham, North Carolina, USA.

Correspondence: Karmel W Choi, Duke University, Department of Psychology and Neuroscience, Box 90086, Durham, North Carolina 27708,

USA. Telephone 480-540-4557, e-mail karmel.choi@duke.edu 
Moreover, the magnitude of the relationship between pain and food intake has not been quantified outside of experimental contexts.

In the current study, we sought to examine the relationship between pain and food intake in a sample of overweight and obese patients with $\mathrm{OA}$ using ecological momentary assessments (EMAs) (35). EMAs involve repeated observations of an individual's experiences and behaviours as they occur in the normal daily environment (36), and offer a suitable naturalistic method to track how pain and food intake may fluctuate in tandem throughout the day in this population. We hypothesized that momentary levels of pain experienced by individual OA patients would account for variations in eating behaviour, such that higher levels of pain would be associated with greater intake of calories, fat and sugar throughout the day.

\section{METHODS}

\section{Participants}

Participants were recruited from a larger intervention trial investigating the separate and combined effects of two behavioural interventions for overweight or obese patients with knee osteoarthritis (37). All eligible patients were $>18$ years of age, with BMIs $\geq 25 \mathrm{~kg} / \mathrm{m}^{2}$, had no other major medical morbidities and met the American College of Rheumatology criteria for $\mathrm{OA}$, with radiographic screening to confirm the presence of $\mathrm{OA}$ in one or both knees (for complete inclusion/exclusion criteria, refer to Somers et al [37]). On completion of the intervention trial, letters were sent to 131 individuals about participating in the present diary study. Seventy-five individuals were enrolled in the diary study. Among those who declined participation, the most frequently cited reasons included being too busy, lack of interest, being lost to contact and having moved out of state. Of those enrolled, four did not complete any assessments. Thus, data from 71 individuals were available for the present diary study.

\section{Design}

Following informed consent, participants completed a baseline assessment in which their height and weight were recorded, and self-reported demographic information was collected. After being educated on EMA rationale and methodology, they were given an electronic beeper and pocket-sized structured paper diary (consisting of two daily booklets) to take home with them. They were trained by a data technician regarding the use of the paper diary system and electronic beeper, and practiced completing sample diary entries. For food intake records, they also received a comprehensive packet of information about estimating standard portion sizes and were encouraged to include food labels and to write down as much information as possible about what they ate and/or drank without specifically weighing intake or calculating calorie amounts.

Participants were scheduled to complete the diary component within one week of their baseline assessment. This component consisted of two consecutive days at their convenience in which participants completed diary entries throughout the day. Individual entries were designed to take no longer than 2 min to complete, and were made on both a random and event-dependent basis. First, entries regarding pain and mood were completed at random intervals in response to the electronic beeper. The beeper was programmed to signal the participants randomly two to three times every hour between 06:00 and 24:00 (excluding sleep hours). Second, entries were self-initiated by participants whenever they were consuming any meal, snack or drink. These event-dependent entries included food records in addition to the usual pain and mood ratings. Participants were instructed to complete their diary entries immediately on being signalled by the beeper or at the time of eating, and to log the exact time of entry. If they were unable to enter the data at the time, they were asked to do so at the next possible opportunity.

During the two days, participants were contacted by a researcher who could troubleshoot technical difficulties and answer any questions. Participants were also instructed to mail back each day's booklet the following morning, and were contacted for follow-up if any diary information was unclear. They were paid $\$ 15$ for each completed daily booklet and an additional $\$ 10$ for complete recording. All procedures were approved by the university Institutional Review Board.

\section{Measures}

Baseline: Height and weight: Weight was measured to the nearest $0.1 \mathrm{~kg}$ using a balance scale. Height was measured to the nearest $1 \mathrm{~cm}$. BMI was calculated by dividing weight $(\mathrm{kg})$ by height $\left(\mathrm{m}^{2}\right)$.

Diary: Pain: Participants rated the intensity of their current pain at each diary entry point using a numerical rating scale ranging from 0 to 10 , with 0 being 'no pain' and 10 being 'worst pain' at that moment. The numerical rating scale is commonly used in pain research (38) and has been found to be a sensitive, reliable and valid measure of subjective pain intensity (39) with demonstrated clinical relevance (40).

Negative mood: Participants rated their negative mood at each diary entry point using single Likert-type items in which they were asked to rate each of three adjectives - angry, nervous and sad - on a scale of 0 to 3, with 0 being 'very much unlike this' and 3 being 'very much like this'. Others have used similar methods of measuring negative mood (41-43); reliability in the current sample was acceptable (Cronbach's alpha $=0.62$ ). A negative mood score was formed from the summed composite of these items, with potential values ranging from 0 to 9 .

Food intake: Participants recorded any intake of food, beverages and/or dietary supplements, and were specifically instructed to include all details such as brand names, preparation methods and amount consumed. Participants were also encouraged to return food labels with their completed daily diary. The food intake records were analyzed by a nutritionist trained in calculating energy density, fat and sugar content of food records using the ESHA Food Processor SQL nutrition program (ESHA Research, USA). This software program has been used for dietary assessment in various health research studies $(44,45)$, and features a comprehensive database of 32,000 foods compiled from 1300 scientific sources of nutrition information. For the analyses presented in the present study, overall calories (in kilojoules) were extracted, as well as the corresponding macronutrient levels of fat and sugar (both in grams). Overall caloric intake was investigated as a marker of overeating. In addition, the present study focused on fat and sugar because previous literature has connected the consumption of these substances with pain relief (17-23).

\section{Data processing and analyses}

Criteria for inclusion in statistical analyses were: if the participant made at least 20 full entries per day over both days of recording; and if corresponding nutritional data were available. Full entries consisted of time of day, pain rating, mood ratings and food intake records if a meal/snack was indicated. According to these criteria, 54 of 71 participants had sufficiently complete diary data across both days. These participants made an average of 33 diary entries per day, yielding a total of 3264 data points for analysis. $\chi^{2}$ and $t$ test analyses were used to examine any differences in the 54 individuals who completed the study compared with the 17 who did not. Differences were examined for sex, age, education, marital status and previous intervention condition. The only difference that emerged was that individuals with incomplete diary data had higher BMI levels compared with those with complete diary data (mean for noncompleters $=$ 36.9 , mean for completers $=32.6 ; \mathrm{t}[69]=2.73 ; \mathrm{P}=0.003$ ). All further analyses only include the 54 participants with complete data.

Generalized estimating equations (GEEs) (46) were used to account for within-subject dependence between observations and to accurately estimate SEs by allowing participants to serve as their own control. First, simple bivariate models were run to test the concurrent relationship between momentary pain and calories, fat or sugar. Three corresponding GEE models were subsequently tested by including a set of a priori variables as covariates. These covariates - sex, BMI, negative mood, time and previous intervention condition - were included as potential confounders due to their associations with both pain and food intake in previous literature (5,47-53). The models were defined using the following equations:

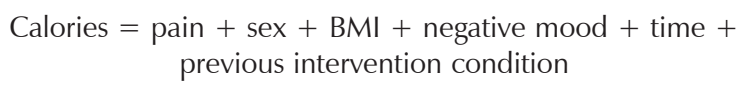

$$
\begin{gathered}
\text { Fat }=\text { pain }+ \text { sex }+ \text { BMI }+ \text { negative mood }+ \text { time }+ \\
\text { previous intervention condition }
\end{gathered}
$$


TABLE 1

\section{Sample demographics}

\begin{tabular}{lccc}
\hline Variable & Total $\mathbf{n}$ & $\mathbf{n}(\%)$ & Mean \pm SD \\
\hline Age, years & 54 & & $62.7 \pm 9.3$ \\
Body mass index, $\mathrm{kg} / \mathrm{m}^{2}$ & 54 & & $32.6 \pm 4.8$ \\
Female sex & 49 & $41(83.7)$ & \\
Race & 53 & & \\
$\quad$ Caucasian & & $34(64.2)$ & \\
$\quad$ African-American/other & & $19(35.8)$ & \\
Married & 48 & $28(58.3)$ & \\
Annual family income & 48 & $41(85.5)$ & \\
$\quad \geq 20,000$ USD & & & \\
Education & 50 & & \\
$\quad$ Less than high school & & & \\
$\quad$ High school degree & & $5(10.0)$ & \\
$\quad$ Some college & & $7(14.0)$ & \\
$\quad$ College degree & & $22(44.0)$ \\
$\quad$ Graduate degree & & $15(30.0)$ & \\
\hline
\end{tabular}

Sugar $=$ pain + sex + BMI + negative mood + time + previous intervention condition

in which sex, BMI and previous intervention condition were betweenperson baseline variables, while pain, negative mood and time were within-person diary variables. For statistical interpretation, the continuous time variable was recoded into a six-level categorical variable reflecting the standard intervals in which the average participant may be expected to consume a meal: midnight to 06:00; 06:00 to 09:00 (breakfast period); $09: 00$ to $11: 00 ; 11: 00$ to $14: 00$ (lunch period); $14: 00$ to $17: 00 \mathrm{pm} ; 17: 00$ to $20: 00 \mathrm{pm}$ (dinner period); and 20:00 to 24:00. All GEE models were run using SAS Genmod (SAS Inc, USA), with the correlational structure set as unstructured.

\section{RESULTS}

\section{Description of sample}

The participants (Table 1$)$ were mostly female $(n=49$ [83.7\%]) and their ages ranged from 42 to 80 years (mean $[ \pm \mathrm{SD}] 62.68 \pm 9.32$ years). Their mean BMI was $32.6 \pm 4.8 \mathrm{~kg} / \mathrm{m}^{2}$ and $69 \%$ were classified as obese. The self-reported racial/ethnic composition was $64.2 \%$ Caucasian and $35.8 \%$ African American/other, and the majority ( $\mathrm{n}=50$ [74\%]) held at least a college or graduate degree. Participants in the present diary study had previously been randomly assigned in the larger intervention trial to the following groups: pain coping skills training (18.5\%); behavioural weight management $(33.3 \%)$; a combination of these two interventions $(27.8 \%)$; or standard care $(20.4 \%)$.

The mean $( \pm \mathrm{SD}$ ) daily diary level of pain was $2 \pm 1.65$ (range 0 to 8 ) and the average negative mood rating was $1 \pm 1.23$ (range 0 to 5 ). The mean total calorie intake per day was $1992 \pm 599$ calories (range 656 to 3941 calories), with an average total of $103 \mathrm{~g}$ fat and $86 \mathrm{~g}$ sugar consumed.

\section{Principal findings}

The primary research hypothesis was that momentary levels of pain would be associated with food intake, as defined by calorie, fat and sugar intake. According to the first GEE model, after adjusting for sex, BMI, negative mood, time and previous intervention condition, pain was a significant predictor of calorie intake $(Z=2.57 ; \mathrm{P}=0.01)$. This suggests that when patients reported higher levels of pain, they also reported eating more calories. Specifically, the model coefficients indicated that for every unit increase in pain rating, there may be an expected increase of 4.25 calories. Sex $(\mathrm{P}=0.007)$ and negative mood $(\mathrm{P}=0.01)$ were also significant predictors of calorie intake, such that being male was related to greater calorie intake, as were lower momentary levels of negative mood. Calories consumed were also significantly higher for the breakfast, lunch and dinner periods $(\mathrm{P}<0.01)$.
In the next model, examining fat intake as the outcome and adjusted for sex, BMI, negative mood, time and previous intervention condition, pain was a significant predictor $(\mathrm{Z}=1.99 ; \mathrm{P}=0.05)$, suggesting that patients experiencing higher levels of momentary pain also consumed more fat. In this model, sex $(\mathrm{P}<0.001)$ and negative mood $(P=0.03)$ significantly predicted fat intake in the same direction as previously, such that being male and lower levels of negative mood were predictive of greater calorie intake. BMI was also a significant predictor $(\mathrm{P}=0.03)$ of fat intake, in that higher $\mathrm{BMI}$ was related to greater intake from moment to moment. Fat intake was also significantly elevated for the lunch and dinner periods $(\mathrm{P}<0.001)$.

In the final model with sugar intake as the outcome, and adjusted for sex, BMI, negative mood, time and previous intervention condition, pain was not found to be a significant predictor $(\mathrm{Z}=1.574$; $\mathrm{P}=0.12)$. Negative mood $(\mathrm{P}=0.01)$ was a significant predictor of sugar intake, such that lower levels of negative mood were predictive of greater sugar intake. Sugar intake was also significantly elevated during the breakfast period $(\mathrm{P}=0.04)$.

\section{Follow-up analyses: practical significance}

To probe the practical significance of pain levels on food intake, followup analyses were conducted for calories and fat, which were significant predictors in earlier analyses. Cutoffs were established, in which momentary pain ratings between 0 and 2 were classified as low pain, ratings between 3 and 6 as moderate pain, and ratings $>7$ as high pain.

$T$ tests comparing high pain to low pain moments across participants indicated that moments in which pain ratings were high differed significantly from moments in which pain ratings were low, in terms of calories eaten $(\mathrm{P}=0.04)$. Specifically, 52 more calories were eaten, on average, during a given moment of high pain compared with low pain (112 kJ and $60 \mathrm{~kJ}$, respectively). Similarly, momentary fat intake also differed significantly between high- and low-pain moments $(\mathrm{P}=0.02)$. Specifically, participants ate more than twice the amount of fat, on average, during a given moment of high pain compared with low pain (5.4 g and $2.4 \mathrm{~g}$, respectively).

There was a similar but nonsignificant trend when comparing calorie intake in high-pain moments to moderate-pain moments $(112 \mathrm{~kJ}$ and $69 \mathrm{~kJ}$ eaten on average, respectively). However, fat intake was significantly higher in high-pain moments compared with moderatepain moments (5.4 $\mathrm{g}$ and $2.7 \mathrm{~g}$ on average, respectively; $\mathrm{P}=0.05$ ).

Comparing moments in which pain ratings were moderate versus low, more calories were eaten on average during moderate-pain moments than in low-pain moments $(69 \mathrm{~kJ}$ and $60 \mathrm{~kJ}$, respectively) although this difference was not statistically significant. Similar to calorie intake, there was a trend toward more fat eaten in moderate pain moments than in low pain moments $(2.7 \mathrm{~g}$ and $2.4 \mathrm{~g}$, respectively), although this was also not significant.

\section{DISCUSSION}

Using an ecological momentary approach, the present study provides novel data supporting a relationship between momentary pain levels and food intake among overweight or obese patients with OA. Our results suggest that patients eat when they experience elevated pain, potentially as a strategy to cope with pain. This behaviour is likely to be counterproductive because it may ultimately result in increased weight, pain and disability. Although previous work has shown that food intake, particularly foods with high caloric content, can produce pain relief (17-23), the present study is the first to quantitatively establish a relationship between higher levels of pain and increased eating in a patient population with persistent pain.

Interestingly, we found that when overweight and obese OA patients reported higher levels of pain, they also reported eating a greater number of calories. This is particularly noteworthy because our analyses adjusted for the potential confounders of sex, BMI, negative mood, time and previous intervention condition. Using a similar model, we also found that patients reported a significant relationship between higher levels of pain and increased fat intake. These observed relationships between pain and both calorie and fat intake extend a recent qualitative study 
using narrative accounts (54) in which overweight individuals with pain reported a desire to consume greater quantities of rich and calorically dense foods when experiencing pain. To our knowledge, our study was the first to begin using quantitative data to explore this relationship. The results contextualize how overweight and obese OA patients may find weight management particularly difficult due to a tendency to eat foods high in calories and fat when experiencing pain. This merits further investigation because foods high in calories or fat may underlie inflammatory and metabolic processes involved in both obesity (55) and pain (56) among OA patients.

We found that levels of negative mood were inversely related to food intake, which suggests that, in moments when patients reported increased negative mood, they were also reporting lower food intake. This was somewhat surprising given literature that suggests that food intake increases during negative mood states $(51,57)$. One possible reason for this finding is that our study is one of the first to examine the relationship between negative mood and food intake while statistically adjusting for pain, and other demographic and medical variables. Previous work has not examined these types of variables simultaneously. Another reason could be related to the brief negative mood scale used in the present study. While we worked to keep the daily diary assessments as least burdensome as possible for the participants, we acknowledge that future research may consider using a more robust measure of negative affect. Finally, it is also possible that participants experienced increased negative mood at times they were not eating, and while they ate their negative mood actually decreased. However, our analyses examined only concurrent relationships between variables, limiting potential inferences about directionality. Future studies are needed to further explore the respective influences of mood and pain on food intake, and to clarify these temporal relationships by carefully examining mood and pain before, during and after food intake.

The present study had several limitations. First, as mentioned previously, our analyses were correlational in nature and did not allow for causal inferences. Follow-up studies could build on the current study's findings to explore potential causal mechanisms (eg, through experimental methods, longitudinal designs and/or cognitive interviewing). Second, participants in the present study were volunteers recruited from a completed intervention trial, which raises issues regarding sample representativeness and intervention effects. However, we adjusted all analyses for previous intervention condition and no significant relationships were found. Future work should extend the current findings by investigating the relationships between pain and eating among overweight and obese OA patients who are naive to behavioural treatments for pain and/or weight management.

Next, levels of food intake were self-reported by all participants and may have been influenced by social desirability bias or problems with recording. We had to exclude $>20 \%$ ( 17 of 71 ) of the participants due to incomplete diary data. These noncompleters were not significantly different from those included in the analyses, except in terms of BMI. It is possible that heavier individuals experienced a greater degree of struggle or shame with eating behaviour and, therefore, were less likely to follow through with consistent self-monitoring. Also, reporting food intake may itself influence eating behaviour (58). Future work should consider methods of collecting data on food intake that do not require conscious monitoring (eg, blood sugar monitors). In addition, participants were allowed to choose their two-day recording window, which could have introduced variability based on eating patterns on weekdays versus weekends. Future studies could consider assigning participants to one weekday and one weekend (eg, Friday and Saturday), or following participants over more days of food recording.

Finally, in our follow-up analyses, we found that $>50$ additional calories were eaten on average during moments of high pain versus low pain. Given the persistent moments of high pain experienced during the day by an individual, this has the potential to accumulate to several hundred extra calories consumed per day, an amount that is clinically relevant for weight gain (59) and deserves further research in this population. At the same time, our main analyses initially showed a relatively modest effect in terms of the number of additional calories consumed while in greater pain (59). Our study was the first to take a naturalistic approach to examine the relationship between pain and eating in participants' everyday environment, which may partially explain the modest relationships found. However, it also represents the first attempt to quantify the magnitude of this potential association and, therefore, would be bolstered by future efforts to both replicate and extend this finding.

Despite the limitations, the present study has important methodological features that should be highlighted. First, we sampled a clinical population of overweight and obese patients with radiographically confirmed knee OA. Second, we extracted detailed nutrition content from participants' food intake records using an established software program. Third, we used EMAs and multilevel modelling, which are particularly advantageous for exploring the relationships between pain and eating throughout the day. EMAs reduce the retrospective biases inherent in dietary recall (60), allowing more accurate estimation of food intake in relation to momentary pain. In addition, EMAs yield naturalistic, ecologically valid data (36) that complement previous experimental studies investigating food intake and pain relief.

Our study suggests that overweight and obese OA patients may find it challenging to resist eating when experiencing high levels of pain, a tendency likely to contribute to excess weight and paradoxically perpetuate $\mathrm{OA}$ pain. This raises implications for clinical care - specifically, the importance of teaching overweight or obese OA patients not only to manage their weight, but also to develop a repertoire of strategies other than eating to cope with their pain. A recent intervention trial involving these patients (37) found that combining both treatment approaches - ie, weight management and pain coping skills training - produced synergistic improvements in pain and weight outcomes. Overweight and obese OA patients in this trial who received both pain and weight management interventions had better outcomes, in terms of both pain and weight, than patients who received either treatment alone or standard care. Future interventions specifically targeting eating as a coping behaviour may prove particularly effective for this population.

\section{CONCLUSION}

We have presented innovative data supporting a relationship between momentary pain, and calorie and fat intake among overweight or obese patients with OA. These findings point toward a complex cycle in which OA pain, food intake and obesity may be mutually reinforced through eating in the presence of pain. Further research investigating eating behaviour as a factor in the maintenance of both pain and obesity will continue to gain relevance as the numbers of individuals with $\mathrm{OA}$ and $\mathrm{OA}$-associated comorbidities, including obesity, continue to rise.

ACKNOWLEDGEMENTS: The authors thank Maggie Rogers for study database support and Michael Coggins for help with diary data entry.

FUNDING: This study was supported by the National Institutes of Health Grant P01 AR50245.

\section{REFERENCES}

1. Arthritis Alliance of Canada. The impact of arthritis in Canada: Today and over the next 30 years. 2011.

2. Helmick CG, Felson DT, Lawrence RC, et al. Estimates of the prevalence of arthritis and other rheumatic conditions in the United States. Part I. Arthritis Rheum 2008;58:15-25.

3. Symmons D, Mathers C, Pfleger B. Global burden of osteoarthritis in the year 2000. Geneva: World Health Organization, 2003.

4. Hunter DJ, McDougall JJ, Keefe FJ. The symptoms of osteoarthritis and the genesis of pain. Med Clin North Am 2009;93:83-100.

5. Marks R. Obesity profiles with knee osteoarthritis: Correlation with pain, disability, disease progression. Obesity 2007;15:1867-74.

6. Creamer P, Lethbridge-Cejku M, Hochberg MC. Determinants of pain severity in knee osteoarthritis: Effect of demographic and psychosocial variables using 3 pain measures. J Rheumatol 1999;26:1785-92.

7. Barofsky I, Fontaine KR, Cheskin LJ. Pain in the obese: Impact on health-related quality-of-life. Ann Behav Med 1997;19:408-10. 
8. Janke EA, Collins A, Kozak AT. Overview of the relationship between pain and obesity: What do we know? Where do we go next? J Rehabil Res Dev 2007:44:245-61.

9. Powell A, Teichtahl AJ, Wluka AE, Cicuttini FM. Obesity: A preventable risk factor for large joint osteoarthritis which may act through biomechanical factors. Br J Sports Med 2005;39:4-5.

10. Riddle DL, Stratford PW. Body weight changes and corresponding changes in pain and function in persons with symptomatic knee osteoarthritis: A cohort study. Arthritis Care Res 2013;65:15-22.

11. Richette P, Poitou C, Garnero P, et al. Benefits of massive weight loss on symptoms, systemic inflammation and cartilage turnover in obese patients with knee osteoarthritis. Ann Rheum Dis 2011;70:139-44.

12. Christensen R, Bartels EM, Astrup A, Bliddal H. Effect of weight reduction in obese patients diagnosed with knee osteoarthritis: A systematic review and meta-analysis. Ann Rheum Dis 2007;66:433-9.

13. Ekman MJ, Klintenberg M, Bjorck U, Norstrom F, Ridderstrale M. Six-minute walk test before and after a weight reduction program in obese subjects. Obesity (Silver Spring) 2013;21:E236-43.

14. Vincent HK, Heywood K, Connelly J, Hurley RW. Obesity and weight loss in the treatment and prevention of osteoarthritis. PM R 2012;4(5 Suppl):S59-S67.

15. Wachholtz A, Binks M, Eisenson H, Kolotkin R, Suzuki A. Does pain predict interference with daily functioning and weight loss in an obese residential treatment-seeking population? Int J Behav Med 2010;17:118-24

16. Howarth D, Inman D, Lingard E, McCaskie A, Gerrand C. Barriers to weight loss in obese patients with knee osteoarthritis. Ann R Coll Surg Engl 2010;92:338-40.

17. Anseloni VCZ, Weng HR, Terayama R, et al. Age-dependency of analgesia elicited by intraoral sucrose in acute and persistent pain models. Pain 2002;97:93-103

18. Harrison D, Johnston L, Loughnan P. Oral sucrose for procedural pain in sick hospitalized infants: A randomized-controlled trial. J Paediatr Child Health 2003;39:591-7.

19. Kakeda T, Ogino Y, Moriya F, Saito S. Sweet taste-induced analgesia: An fMRI study. Neuroreport 2010;21:427-31.

20. Lewkowski MD, Ditto B, Roussos M, Young SN. Sweet taste and blood pressure-related analgesia. Pain 2003;106:181-6.

21. Segato FN, CastroSouza C, Segato EN, Morato S, Coimbra NC. Sucrose ingestion causes opioid analgesia. Braz J Med Biol Res 1997;30:981-4.

22. Pérez J, Ware MA, Chevalier S, Gougeon R, Bennett GJ, Shir Y. Dietary fat and protein interact in suppressing neuropathic pain-related disorders following a partial sciatic ligation injury in rats. Pain 2004;111:297-305.

23. Shide DJ, Blass EM. Opioidlike effects of intraoral infusions of corn oil and polycose on stress reactions in 10-day-old rats. Behav Neurosci 1989;103:1168-75.

24. Zmarzty SA, Wells AS, Read NW. The influence of food on pain perception in healthy human volunteers. Physiol Behav 1997;62:185-91.

25. Mercer ME, Holder MD. Antinociceptive effects of palatable sweet ingesta on human responsivity to pressure pain. Physiol Behav 1997;61:311-8.

26. Christensen L. The effect of carbohydrates on affect. Nutrition 1997;13:503-14.

27. Leigh Gibson E. Emotional influences on food choice: Sensory, physiological and psychological pathways. Physiol Behav 2006;89:53-61.

28. Macht M, Mueller J. Immediate effects of chocolate on experimentally induced mood states. Appetite 2007;49:667-74.

29. Markus R, Panhuysen G, Tuiten A, Koppeschaar H. Effects of food on cortisol and mood in vulnerable subjects under controllable and uncontrollable stress. Physiol Behav 2000;70:333-42.

30. Wallis DJ, Hetherington MM. Emotions and eating. Self-reported and experimentally induced changes in food intake under stress. Appetite 2009;52:355-62.

31. Kracke GR, Uthoff KA, Tobias JD. Sugar solution analgesia: The effects of glucose on expressed mu opioid receptors. Anesth Analg 2005;101:64-8.

32. Kanarek RB, Przypek J, D'Anci KE, Marks-Kaufman R. Dietary modulation of mu and kappa opioid receptor-mediated analgesia. Pharmacol Biochem Behav 1997;58:43-9.

33. Slochower J, Kaplan SP, Mann L. The effects of life stress and weight on mood and eating. Appetite 1981;2:115-25.
34. Lieberman HR, Wurtman JJ, Chew B. Changes in mood after carbohydrate consumption among obese individuals. Am J Clin Nutr 1986;44:772-8.

35. Stone AA, Shiffman S. Ecological momentary assessment (EMA) in behavorial medicine. Ann Behav Med 1994:16:199-202.

36. Shiffman S, Stone AA, Hufford MR. Ecological momentary assessment. Annu Rev Clin Psychol 2008;4:1-32.

37. Somers TJ, Blumenthal JA, Guilak F, et al. Pain coping skills training and lifestyle behavioral weight management in patients with knee osteoarthritis: A randomized controlled study. Pain 2012;153:1199-209.

38. Kahl C, Cleland JA. Visual analogue scale, numeric pain rating scale and the McGill Pain Questionnaire: An overview of psychometric properties. Physical Therapy Reviews 2005;10:123-8.

39. Williamson A, Hoggart B. Pain: A review of three commonly used pain rating scales. J Clin Nurs 2005;14:798-804.

40. Farrar JT, Young JP, Jr., LaMoreaux L, Werth JL, Poole RM. Clinical importance of changes in chronic pain intensity measured on an 11-point numerical pain rating scale. Pain 2001;94:149-58.

41. Marco CA, Suls J. Daily stress and the trajectory of mood: Spillover, response assimilation, contrast, and chronic negative affectivity. J Pers Soc Psychol 1993;64:1053-63.

42. Reid SC, Kauer SD, Dudgeon P, Sanci LA, Shrier LA, Patton GC. A mobile phone program to track young people's experiences of mood, stress and coping. Development and testing of the mobiletype program. Soc Psychiatry Psychiatr Epidemiol 2009;44:501-7.

43. Armeli S, Tennen $\mathrm{H}$, Todd M, et al. A daily process examination of the stress-response dampening effects of alcohol consumption. Psychol Addict Behav 2003;17:266-76.

44. Bazzano LA, He J, Ogden LG, Loria CM, Whelton PK. Dietary fiber intake and reduced risk of coronary heart disease in US men and women: The National Health and Nutrition Examination Survey I Epidemiologic Follow-up Study. Arch Intern Med 2003;163:1897-904.

45. Ballesteros MN, Cabrera RM, Saucedo MS, Yepiz-Plascencia GM, Ortega MI, Valencia ME. Dietary fiber and lifestyle influence serum lipids in free living adult men. J Am Coll Nutr 2001;20:649-55.

46. Liang K-Y, Zeger SL. Longitudinal data analysis using generalized linear models. Biometrika 1986;73:13-22.

47. Keefe FJ, Lefebvre JC, Egert JR, Affleck G, Sullivan MJ, Caldwell DS. The relationship of gender to pain, pain behavior, and disability in osteoarthritis patients: The role of catastrophizing. Pain 2000;87:325-34.

48. Rolls BJ, Fedoroff IC, Guthrie JF. Gender differences in eating behavior and body weight regulation. Health Psychol 1991;10:133-42.

49. Howarth NC, Huang TT, Roberts SB, Lin BH, McCrory MA. Eating patterns and dietary composition in relation to BMI in younger and older adults. Int J Obes 2006;31:675-84.

50. Huyser BA, Parker JC. Negative affect and pain in arthritis. Rheum Dis Clin North Am 1999;25:105-21.

51. Patel KA, Schlundt DG. Impact of moods and social context on eating behavior. Appetite 2001;36:111-8.

52. Bellamy N, Sothern RB, Campbell J. Rhythmic variations in pain perception in osteoarthritis of the knee. J Rheumatol 1990;17:364-72.

53. Ma Y, Bertone ER, Stanek EJ, et al. Association between eating patterns and obesity in a free-living US adult population. Am J Epidemiol 2003;158:85-92.

54. Janke EA, Kozak AT. "The more pain I have, the more I want to eat": Obesity in the context of chronic pain. Obesity 2012;20:2027-34.

55. Bullo M, Casas-Agustench P, Amigo-Correig P, Aranceta J, Salas-Salvado J. Inflammation, obesity and comorbidities: The role of diet. Public Health Nutr 2007;10:1164-72.

56. Felson DT. The sources of pain in knee osteoarthritis. Curr Opin Rheumatol 2005;17:624-8.

57. Chua JL, Touyz S, Hill AJ. Negative mood-induced overeating in obese binge eaters: An experimental study. Int J Obes Relat Metab Disord 2004;28:606-10.

58. Burke LE, Wang J, Sevick MA. Self-monitoring in weight loss: A systematic review of the literature. J Am Diet Assoc 2011;111:92-102.

59. Katan MB, Ludwig DS. Extra calories cause weight gain - but how much? JAMA 2010;303:65-6.

60. Smyth J, Wonderlich S, Crosby R, Miltenberger R, Mitchell J, Rorty M. The use of ecological momentary assessment approaches in eating disorder research. Int J Eat Disord 2001;30:83-95. 


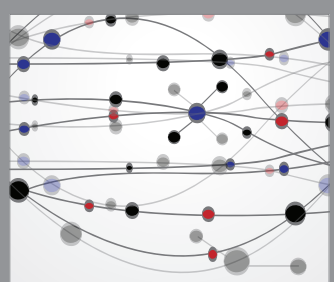

The Scientific World Journal
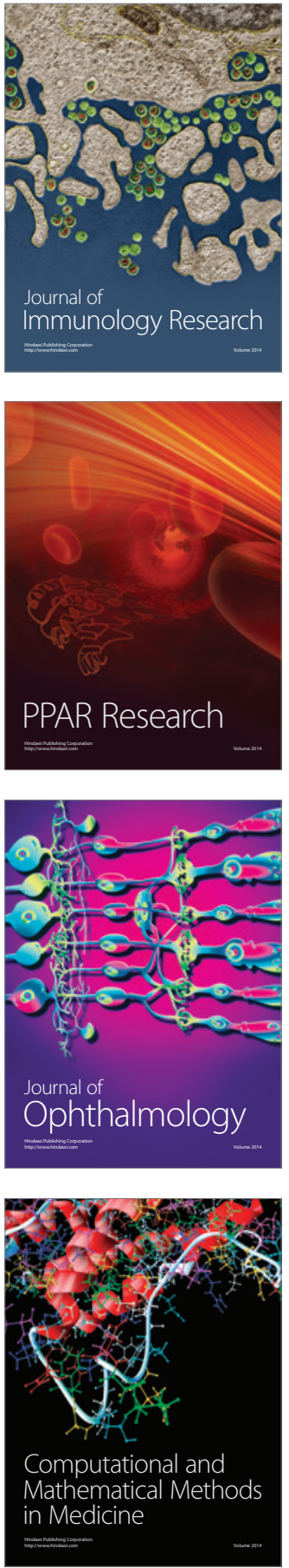

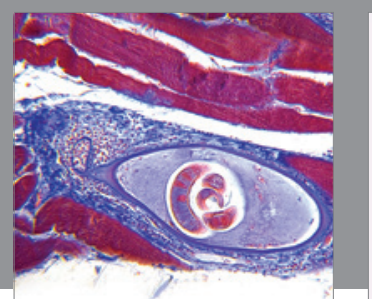

Gastroenterology Research and Practice

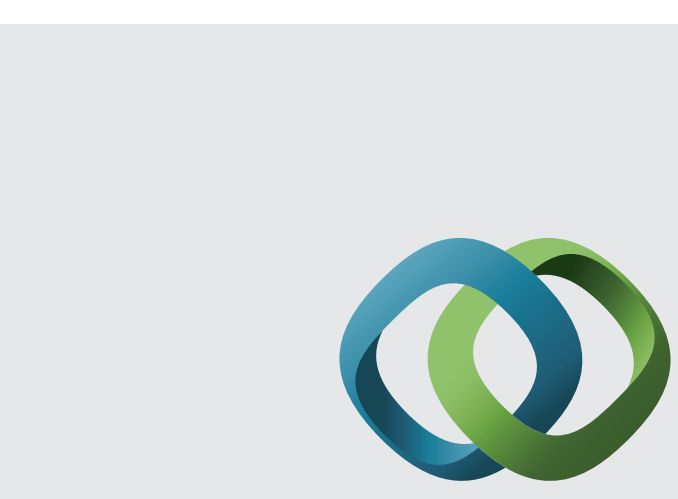

\section{Hindawi}

Submit your manuscripts at

http://www.hindawi.com
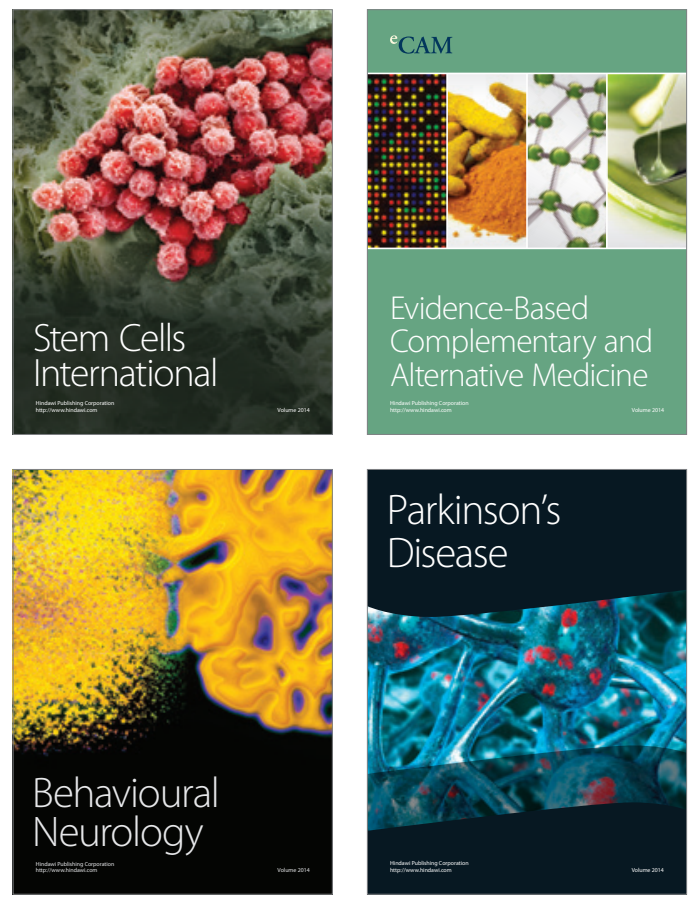
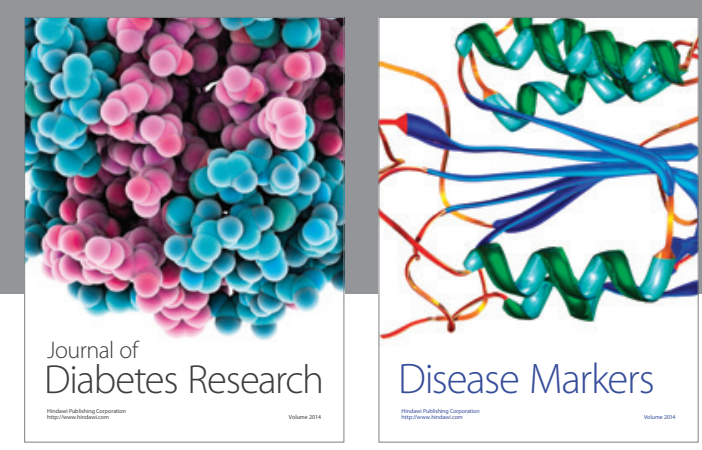

Disease Markers
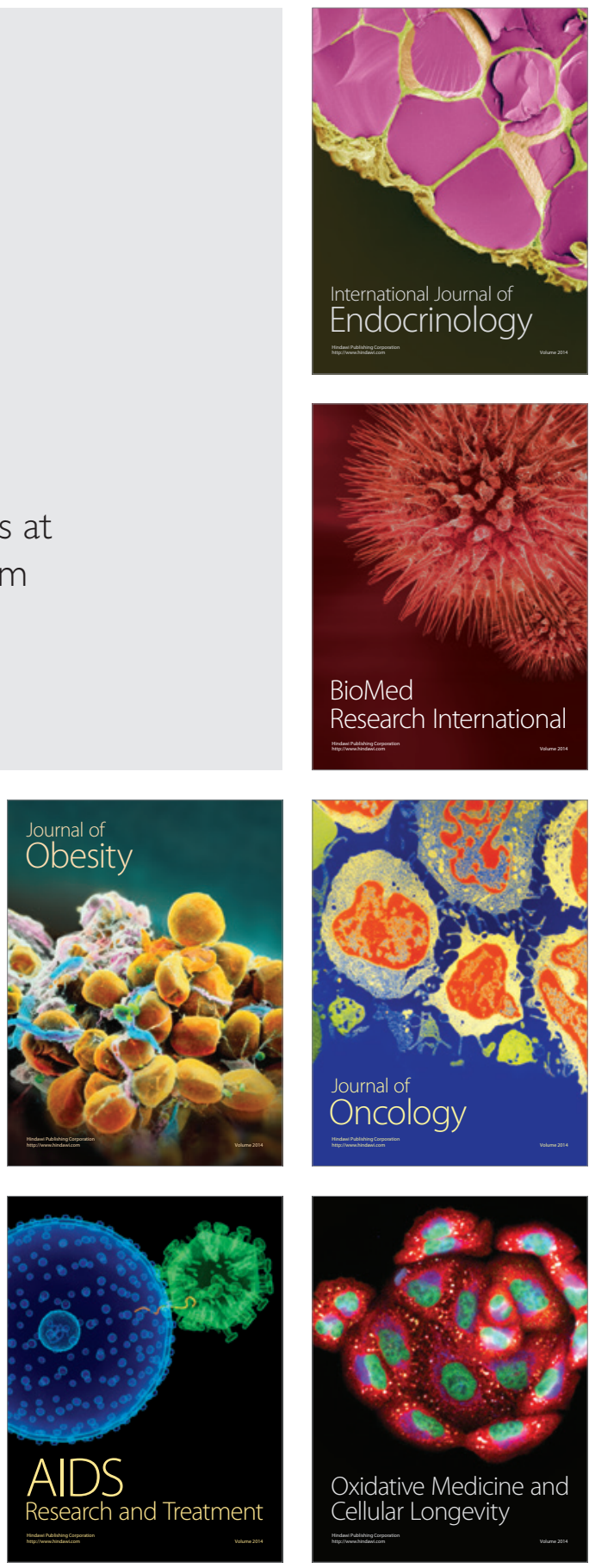